SAT0583-HPR (2013)

\title{
DIFFERENCES BETWEEN SERVICE PROVIDERS AND USERS WHEN DEFINING FEASIBLE OPTIMAL NHS OCCUPATIONAL THERAPY TREATMENT FOR PATIENTS WITH THUMB BASE OA: RESULTS FROM A DELPHI STUDY
}

\author{
S. Barbosa Boucas', K. Hislop Lennie', K. Dziedzic², N. Arden³, J. Burridge', A. \\ Hammond ${ }^{4}$, M. Stokes', M. Lewis ${ }^{2}$, R. Gooberman-Hillis, K. Coales'1, J. Adams ${ }^{1}$ \\ ${ }^{1}$ Faculty of Health Sciences, University of Southampton, Southampton \\ ${ }^{2}$ Institute of Primary Care \& Health Sciences, Keele University, Keele \\ ${ }^{3}$ The Botnar Research Centre Institute of Musculoskeletal Sciences, University of Oxford, \\ Oxford \\ ${ }^{4}$ Centre for Rehabilitation \& Human Performance Research, University of Salford, Salford \\ ${ }_{5}$ Musculoskeletal Research Unit, University fo Bristol, Bristol, United Kingdom
}

Background: The OTTER (OsTeoarthritis Thumb ThERapy) trial is a two-year developmental study for a full randomised controlled trial (RCT) into the clinical and cost effectiveness of an occupational therapy and splint intervention for thumb base OA. To develop an optimal package of care for evaluation within a multi-centre RCT, the views of both clinicians and patients are crucial.

Objectives: To conduct a Delphi study to obtain agreement between both patients with thumb base OA and AHPs concerning the most appropriate optimal NHS OT programme, splint and placebo splint intervention to use in the RCT.

Methods: The Delphi panel consisted of 63 AHPs experienced in treating adults with thumb base OA, and 7 patients with thumb base OA. The panel were asked to rate how much they agreed or disagreed about what optimal NHS OT care for thumb base OA should include, and what method(s) of delivery (individual one-to-one, group, patient leaflets, or telephone advice) they deemed were more appropriate. The Delphi study comprised 3 rounds. A seven-point Likert-type scale was used. Pre-defined inclusion and exclusion criteria were applied in order to reach a final number of statements which, in turn, created the desired tool. Group differences were analysed using Mann-Whitney U tests.

Results: Between-groups analyses showed significant differences in the ratings of overall importance of items to be included in an optimal NHS OT consultation (Table 1).

Table 1. Between-group differences for items importance.

\begin{tabular}{|c|c|c|c|}
\hline Item & $\mathrm{AHPs}^{*}$ & Patients* & $P$ \\
\hline Treatment Options & 2.00 & 1.00 & 0.041 \\
\hline Prognosis Advice & 2.00 & 1.00 & 0.006 \\
\hline $\begin{array}{l}\text { Referral to other Health Care } \\
\text { Professional }\end{array}$ & 3.00 & 1.00 & 0.001 \\
\hline NHS Clinic Procedures & 3.00 & 1.00 & 0.013 \\
\hline $\begin{array}{c}\text { Sleep Assessment and } \\
\text { Management }\end{array}$ & 3.00 & 2.00 & 0.004 \\
\hline $\begin{array}{c}\text { Education for Family/Significant } \\
\text { Others/Carers }\end{array}$ & 3.00 & 2.00 & 0.041 \\
\hline
\end{tabular}

Scores are Round 3 medians. Importance: 1='Definitely important', 2='Very important', 3='Slightly important', 4= 'Undecided/Not sure', 5= 'Slightly unimportant', $6=$ 'Very unimportant', $7=$ 'Definitely unimportant'

There were significant differences in the methods of delivery, with patients rating higher than AHPs (Table 2).

Table 2. Between-group differences for method of delivery to be used.

\begin{tabular}{|c||c|c|c|}
\hline Type of Delivery & AHPs $^{*}$ & Patients & P \\
\hline \hline One-to-one & 2.00 & 1.00 & 0.004 \\
\hline \hline Leaflets & 3.00 & 1.00 & 0.002 \\
\hline \hline Telephone & 4.00 & 1.00 & 0.008 \\
\hline \hline Group & 6.00 & 1.00 & 0.002 \\
\hline
\end{tabular}

Conclusions: AHPs and patients differed in their views about the importance of including 'Education for Family/Significant Others/Carers', 'NHS Clinic Procedures', 'Prognosis Advice', 'Referral to other Health Care Professional', 'Sleep Assessment and Management' and 'Treatment Options' in an optimal NHS OT consultation, and in the methods of delivery used in the consultation. AHPs placed significantly less importance than patients on 'One-to-One Contact', 'Leaflets' and 'Telephone Advice'. These findings demonstrate the importance of consultingwith patients at an early stage in developing an intervention. 
Disclosure of Interest: None Declared

Citation: , Ann Rheum Dis 2013:72 S3; 779-780

Session: Poster session Saturday () 